\title{
Students' referral causes to counselling services of Ahvaz Jundishapur University of medical sciences, Southwest of Iran
}

\author{
Shakurnia, A. ${ }^{1}$, Mohtadi, A. ${ }^{2}$, B Bijanzadeh, M. ${ }^{3}$
}

\begin{abstract}
Introduction: The university counselling services have a fundamental role in guiding of students. These centers provide counselling affairs for students who need help to overcome their problems and successfully complete their education. This study designed to determine referral causes of students to counseling services in Ahvaz Jundishapur University of Medical Sciences.
\end{abstract}

Methods: In this cross-sectional study, referral causes of 132 students to counseling services at oneyear period were analyzed. Data of this study were extracted from the recording notes of these centers. The data were analysed by chi-square test.

Results: Of 1300 students, $132(10.15 \%)$ had at least one referral to the University counseling services. Dental students referred to these centers more than medical students $(18.3 \%$ vs. $8.8 \%, x 2=15.71$ and $p=0.02)$. The main referral causes were: education problems $(17.4 \%)$, emotional problems $(29.8 \%)$, individual problems $(25.8 \%)$, marital problems $(20.5 \%)$ and family problems $(6.1 \%)$. The chi-square analysis indicated significant differences for referral causes of students by marital and native status $(\mathrm{p}=0.023$ and 0.010 respectively).

Conclusion: The number of referrals to the University counselling services suggest that these adopting of these centres by students as representative of necessary counselling affairs. In the present study, most common referral causes to these services were emotional and individual problems.

Key word: counselling service, referral cause, student problems

\section{Introduction}

After students of high schools pass national university entrance exams and enter universities, changes in social, cultural and discipline conditions and development of communications can lead them to very important challenges.

\footnotetext{
${ }^{1}$ Assistant Professor, Immunology Department

${ }^{2}$ Assistant Professor, Anesthesia Department

${ }^{3}$ Assistant Professor, Genetics Department

Medical Faculty, Ahvaz Jundishapur University of Medical Sciences, Ahvaz, Iran.

Corresponding Author:

Mahdi Bijanzadeh, Assistant Professor, Genetics Department, Medical Faculty, Ahvaz Jundishapur University of Medical Sciences, Ahvaz, Iran.

Email:mbijanz@yahoo.com
}

With regards to students' age, their need for conformity with the new environment and management of educational, emotional and economic problems, the first years of study are very important. Proper counselling is one of the needs and an effective measure for resolving many related problems, so the counsellor can help them by increasing of knowledge, motive and skills to diagnose the problem and understanding decision (Paykari et al., 2007).

Students encounter many problems during their education. Educational, individual, psychological, mental and social problems have been considered very important for the students and lack of control for these problems decreases the academic achievement. Looking into the problems of students referring them to university counselling services can be used as an important index in the identification of level and type of students' problems (Paykari et al., 
2007, Ceyhan et al., 2011, Reem et al., 2009 revealed that academic problems were greater sources of stress in first year medical students compared to non-academic problems. Many studies have shown that stress levels of medical students are absolutely high. It has been reported that medical students compared to the general population, have more distress, anxiety and depression (Mahajan, 2010). Studies indicated that $3-12 \%$ of the students eligible in universities of Iran have referred to university counselling services due to individual and educational problems (Sam et al., 2012).

The university counselling services have the main role in leadership and gaudiness of students. They help students, specially the recent- entered ones, by counselling for defence against stressor agents, same as family missing worry, adaption with academic live condition, sharing accommodation in hostels, time utilization, budget management and etc., so they can win their socio-cultural and educational challenges, and graduated successfully (Ceyhan et al., 2011). The university counselling services have been established at 1995 in medical Universities of Iran. The goals of these services are: support of prone students to mental injuries, and helping students in diagnosis of their conditions, especially adaption by university's dependences, entrance to academic live condition, management of educational, emotional and economic problems that result enhancement of thinking power, abilities, selections and decision making powers in important steps of the live (Sam et al., 2012).

Review of national and international literatures showed that these services had a strong impact in counselling affairs for students (Flisher et al., 2002, Daroonparvar, 2005). Radolf by analysing effects of counselling services in management of students' problem showed that counselling can play an important role in adaption of students by their condition (Flisher et al., 2002). A study at Baskent University in Turkey showed that $20.2 \%$ of students referred to university counselling services for receiving counselling affairs (Dogan, 2012). In another study only $3 \%$ of 4699 students of a University in U.K. have referred to counselling services of their university (Cooke et al., 2006). In mentioned studies mental, educational and communication problems were important causes of refers to university counselling services.

National studies in Iran cleared high impact of university counselling services in students' health and also high prevalence of mental disorders in students referred to emergency clinics of these services (Bahari, 2001; Daroonparvar, 2005). Ferdowsi (2003) after analysis of 1907 students' documents referred to university counselling services in Tehran, mentioned that the most common problems of these students were mental problems and education problems. Evaluation the students refers to counselling services of Khoram Abad University showed the common causes of refers were mental, familial and educational problems (Sepahvandi, 2003). Results of other studies carried out by evaluation of referral causes in some universities are generally similar with some differences (Naze et al., 2001, Shakurnia et al., 2011). Common results showed $3-5 \%$ of students referred to university counselling services for their familial, educational and mental problems; additionally, mental status of students studied in their city (native students) is better than non-native. Although female students have better educational condition compare to males, but they have more mental problems than male students, so the need more counselling affairs (Fazeli et al., 2004).

With attention to quantitative studies about function of university counselling services, more future studies are very helpful to detect special referral causes and counselling needful. This study has been designed to determine referral causes to counselling services of Ahvaz Jundishapur University of medical sciences, Iran.

\section{Methods}

In this descriptive cross-sectional study, referral causes of 132 students to the counselling services of Ahvaz Jundishapur University of medical sciences during one year have been analysed. The population in this study was medical and dental students were studying during 2012. Cases were students have referred to the counselling services of this University due to their problems and their information had been recorded and analysed in personal documental sheets (132 students). Their personal data including demographic information and their referral causes have been obtained and saved in data bank of study. The data has been collected by the service's clerk and gave to researcher. For confidence of information, data of students was submitted bycode and un-noun.

For better categorize and more simple analysis, similar referral causes of students to counselling services have been divided to 5 groups: educational problems, family problems, 
marital problems, emotional problems and individual problems. Some examples of educational problems were: non-inclination to field of study, prominent decreasing in remarks, gross failing of semester, etc. The family problems were included: matrimony problems, challenges with partner or paternal family and addiction of relatives. Marital problems also were included: marriage consult, selection of partner and family planning. Some instances of emotional problems were stress, obsession, anxiety, depression, exile worry, low selfesteem, nervous and mania; and individual problems were non-conciseness, doubt in decision, interpersonal problems, smoking and HIV infection.

Data was analysed by SPSS software. Frequency and percentile were used to describe the results. Chi square test was used for relationship of data.

\section{Results}

Out of 132 students referred to the counselling services of Ahvaz Jundishapur University of medical sciences during 2012, 58 (44\%) were male and 74 (56\%) were female; 97 (73.9\%) were stayed in hostels of University and others (25.8\%) were not; 64 (48\%) were native and stayed at Khouzestan province and others 70 $(52 \%)$ stayed at other provinces of Iran (notnative); 120 (91\%) were single and 12 (9\%) were married; $98(74.2 \%)$ were studied medicine and $34(25.8 \%)$ were studied dentistry. Mean and standard division of students' age was $22.05 \pm 2.9$ and age range was $18-30$ years.
37 students (28\%) had only one refer, and 45 (34\%), 30 (23\%), 12 (9\%) and 8 students (6\%) had respectively: two, three, four and more than four refers to counselling services of University. Mean of students refers to these services was $2.23 \pm 1.2$, that was $2.30 \pm 1.23$ for females and $2.38 \pm 1.20$ for males $(p=0.70)$.

Out of 1300 medical and dental students of this University, 132 students (10.15\%) referred at least one time to counselling services of University for planning their problems and using of counselling affairs. Male students referred to these services more than females, but without significant differences ( $11 \%$ vs. $9.6 \%, x 2=0.67$ and $p=0.23)$. Dental students had significantly more refers than medical students (18.3\% vs. $8.8 \%, x 2=15.71$ and $p=0.0001$ ) (Table 1). 23 students $(17.4 \%)$ referred to these centers due to educational problems, 40 (29.8\%) due to emotional problems, $34(25.8 \%)$ due to individual problems, $27(20.5 \%)$ due to marital problems and 8 students $(6.1 \%)$ due to familial problems. The chi-square test indicated that there were significant differences between causes of refers depends on their marital condition $(x 2=11.34$ and $p=0.023)$ and their native condition $(x 2=13.28$ and $p=0.010)$. Single students had more individual and emotional problems; and married students had more educational problems. Native students referred to counselling services dominantly due to educational and marital problems, while dominant causes of non-native students were emotional and individual problems.

Table1: Frequencies of students' referral to counselling services

\begin{tabular}{llrrr}
\hline Faculty & \multicolumn{1}{c}{ Students' no. } & Male No. (\%) & Female No. (\%) & Total No. (\%) \\
\hline \multirow{2}{*}{ Medicine } & Total & $447(84.6)$ & $667(85.4)$ & $1114(86.0)$ \\
& Referred to centers & $42(72.4)$ & $56(76.7)$ & $98(74.2)$ \\
& Total & & & $186(14.0)$ \\
Dental & Referred to centers & $81(15.4)$ & $16(13.6)$ & $34(25.8)$ \\
& Total & $16(27.6)$ & $18(24.3)$ & $1300(100.0)$ \\
& Referred to centers & $528(42.0)$ & $772(58.0)$ & $132(100.0)$ \\
\hline
\end{tabular}


There was no significant difference between referral cause of male and female students stayed in hostels and not stayed in hostels (Table 2).

The chi-square test showed there was significant difference between problems of medical and dental students $(x 2=18.69$ and $\mathrm{p}=0.001$ ): medical students referred to counselling services due to emotional and marital problems more than other causes, while dominant cause of dental students were individual and educational problems (Table 3). Thirty-six students $(27.5 \%)$ were first year students, 45 (34.4\%), 30 (22.5\%) and 20 $(15.5 \%)$ of them were second, third and fourth and more year students, respectively. The first and second year students had educational and familial problems dominantly; but third and fourth students referred to counselling services due to emotional problems more than other causes $(x 2=18.69$ and $p=0.001)$.

Table 2: Comparison of frequencies of students' referral causes to counselling services

\begin{tabular}{|c|c|c|c|c|c|c|c|c|c|}
\hline \multicolumn{2}{|c|}{ Variables } & \multicolumn{5}{|c|}{ Percentiles of referral causes } & \multirow{2}{*}{$\begin{array}{c}\text { Refers } \\
\text { no. } \\
(\mathrm{N}=132)\end{array}$} & \multirow[b]{2}{*}{$x^{2}$} & \multirow[b]{2}{*}{$p$} \\
\hline & bles & $\begin{array}{l}\text { Individual } \\
\quad(N=34)\end{array}$ & $\begin{array}{c}\text { Emotional } \\
(\mathrm{N}=40)\end{array}$ & $\begin{array}{l}\text { Marital } \\
(\mathrm{N}=27)\end{array}$ & $\begin{array}{l}\text { Family } \\
(\mathrm{N}=8)\end{array}$ & $\begin{array}{c}\begin{array}{c}\text { Educat } \\
\text { ion } \\
(\mathrm{N}=23)\end{array} \\
\end{array}$ & & & \\
\hline \multirow[b]{2}{*}{ Sex } & Male & 19.0 & 37.9 & 15.5 & 10.3 & 17.2 & 58 & \multirow[b]{2}{*}{8.79} & \multirow[b]{2}{*}{0.060} \\
\hline & Female & 31.5 & 23.3 & 24.7 & 2.7 & 17.8 & 74 & & \\
\hline \multirow[b]{2}{*}{ Marital } & Single & 25.2 & 31.9 & 21.8 & 6.7 & 14.3 & 120 & \multirow[b]{2}{*}{11.34} & \multirow[b]{2}{*}{0.023} \\
\hline & Married & 23.3 & 8.3 & 8.3 & 0 & 50 & 12 & & \\
\hline \multirow{3}{*}{ Location } & Native & 16.9 & 23.7 & 23.7 & 6.8 & 28.8 & 64 & \multirow{3}{*}{13.28} & \multirow{3}{*}{0.010} \\
\hline & & & & & & & & & \\
\hline & Non-native & 33.8 & 36.9 & 15.4 & 4.6 & 9.2 & 70 & & \\
\hline \multirow{3}{*}{ Place } & Hostel & 21.8 & 32.3 & 18.8 & 6.3 & 14.6 & 97 & \multirow{3}{*}{3.37} & \multirow{3}{*}{0.490} \\
\hline & & & & & & & & & \\
\hline & No hostel & 20.6 & 23.5 & 23.5 & 5.9 & 26.5 & 35 & & \\
\hline
\end{tabular}

Table 3: Frequencies and percentiles of students' referral causes to counselling services in different faculties

\begin{tabular}{|c|c|c|c|c|c|c|c|c|}
\hline \multirow{2}{*}{ Faculty } & \multicolumn{5}{|c|}{ Percentiles of referral causes } & \multirow{2}{*}{$\begin{array}{c}\text { Refers } \\
\text { no. } \\
\text { N=132 }\end{array}$} & \multirow[b]{2}{*}{$x^{2}$} & \multirow[b]{2}{*}{$p$} \\
\hline & $\begin{array}{l}\text { Individual } \\
(\mathrm{N}=34)\end{array}$ & $\begin{array}{c}\text { Emotional } \\
(\mathrm{N}=40)\end{array}$ & $\begin{array}{l}\text { Marital } \\
(\mathrm{N}=27)\end{array}$ & $\begin{array}{c}\text { Family } \\
(\mathrm{N}=8)\end{array}$ & $\begin{array}{l}\text { Education } \\
\qquad(\mathrm{N}=23)\end{array}$ & & & \\
\hline Medicine & 17.5 & 36.1 & 23.7 & 7.2 & 15.5 & 98 & & \\
\hline Dental & 11.8 & 11.8 & 2.9 & 23.5 & 34 & 34 & 18.69 & 0.001 \\
\hline Total & 26 & 29.8 & 20.6 & 6.1 & 17.6 & 132 & & \\
\hline
\end{tabular}




\section{Discussion}

This study that carried out to analysis referral causes of medical and dental students to counselling services of Ahvaz Jundishapur Universities of medical sciences showed that around $10 \%$ of these students had at least one refer during two semesters to counselling services of this University for their problems. The mean of refers was 2.33 , that is similar to results of two similar studies reported 2.5 and 3 (Quintrell et al., 1996; McCormick et al., 1996). Results of a study in Turkey showed that students had more problems during studying period, had more refers to university counselling services (Giorazolias et al., 2010).

Present study resulted that the most common important problems which referred students to dissolve them in counselling services were emotional and individual problems, and then marital, educational and familial problems. These results relatively correlated with results of other Universities (Ferdowsi et al., 2003; Dogan, 2012). Sepahvandi (2003) showed that the most referral causes to counselling services of Lorestan University, during two semesters were emotional, familial and educational problems that relatively correlated with our findings. Evaluation of referral causes to university counselling services in Tehran city showed that emotional, educational and familial problems were the most common by $42.5 \%$, $22 \%$ and $15.5 \%$ respectively (Ferdowsi et al., 2003).

The most common referral cause to counselling services of some Universities in U.K. revealed emotional, communicational and education problems (Connell et al., 2007), these causes for Universities of Turkey were educational and then individual and psychological problems (Dogan, 2012). The individual characteristics of students involved in studies, climatic and environmental conditions might be caused mentioned differences.

Present study showed that the most common referral causes of single students to counselling services of Ahvaz Jundishapur University were emotional and marital problems, while married students commonly referred these services due to educational and individual problems. These are similar to results of Ferdowsi's study in Universities of Tehran city that reported emotional problems as the most common referral cause of single students (Ferdowsi, 2003). Probably single students experienced more emotional challenges due to their alone condition and distance from family, so they have more problems compare to married ones that have more mental stability. This point highlights the impact of these services for single students.

The most common referral causes of native students to counselling services of Ahvaz Jundishapur University were educational and marital problems, while not-native ones commonly referred due to emotional and individual problems. More psycho-emotional and social problems of not-native students, especially in entrancing time to university, are resulted from family distance and subsequent interpersonal evidences in the university. Therefore, non-native students have more individual and emotional problems, and more refers to counselling services, compare to native students. Results of different studies showed that emotional problem was one of the most important and common referral cause to university counselling services (Gunneri et al., 2004; Atik et al., 2012).

Analysis of correlation between residential place of students and their problems showed that majority of students referred to counselling services were hostel- stayed (82.6\%). Ferdowsi (2003) also reported similar fact for students of universities in Tehran city: he reported that hostel - stayed students had more refers to counselling services due to any causes. This increase in frequency may relate to high frequency of hostel- stayed students compare with home-stayed ones. Although in some cases, emotional problems were more frequent in hostel - stayed students; there was no significant difference between residential condition of students and their problems. High frequency of hostel- stayed students' problems and their more refers to counselling services of universities, recommended comprehensive planning for presentation of hostels' needs and dissolving of emotional problems of students stayed in hostels.

Data also resulted more students' studying time, less referred to counselling services. On the other hand, in beginning years of studying time, regarding un-known features of university, more stresses and educational problems, students need more to counselling affairs. Researchers believed distance between students and their family, entrance to wide and non-familiar condition of university and new educational condition result their confusion that leading them to counselling services (Benton et al., 2003; Arco et al., 2005). Another important 
fact showed increasing staying time of students in university, changes the feature of their This means in the first years of studying period, the main referral causes of students to counselling services were educational and familial problems, but at the last year of studying, they referred to dissolve their emotional problems. Investigators believed that when students near to graduation, they are planning to marriage and taking a suitable job, so un-known future may lead them to emotional stress and refers to counselling services (Raunic et al., 2008; Lucas et al., 2005).

Fisher (2002) after comparison of referral causes of students to counselling services of University of Cape Town, South Africa revealed a significant decreased refers during their presence in university lengthened after the admittance year to university. He showed that the freshman and sophomore students had more referred to counselling services due to educational, individual and family problems, while, junior and senior students had more referred due to psychological, emotional and marital problems. Also, junior students had more problems than senior ones. The new students probably experienced more problems and stress due to unfamiliarity with the campus. Researchers believe that moving away from the family and entering university and new academic condition baffle the students and make them refer to counselling services (Fisher, 2002). Analysis of relationship between subject of students and their problems showed different cause and time of refers between medical and dental students. Dental students had more refers compared to medical students, and generally counselled about their individual and educational problems, while the main referral causes of medical students were emotional and marital problems. Ferdowsi (2003) after studying the problems referred students to counselling services of universities in Tehran city, reported that the students of Humanity had more refers. He showed a significant difference between subject of students and their causes of refers to counselling services. Probably current condition, feature and future of each subject contribute different problems for their students.

Although some researchers showed differences causes and times of refers between male and female students (Dogan, 2012; Dogan et al., 2007), in this study that male students had more refers and emotional problems than females, were no significant differences between gender of students and their causes and times of refers to counselling problems: educational and familial problems decrease, while emotional problems increase. services. This result may be actual, and may be related to less number of subjects in this study.

The findings of present study indicated that the most important problems of the students were educational, emotional, individual, marital and family problems respectively. Identification of the referral causes of students, their classification, analysis and presentation of practical solutions to decrease their negative effects can influence the students' academic improvement. Results of this study showed that counselling services of universities as representative of necessary counselling affairs are referral centers for planning of students' problems.

Short conclusion: The most important problems of medical and dental students referred to counselling services of Ahvaz Jundishapur University of medical sciences were educational, emotional, individual, marital and family problems respectively. Identification of the referral causes of students, their classification, analysis and presentation of practical solutions to decrease their negative effects can influence the students' academic improvement, and so counselling services of universities as representative of necessary counselling affairs are referral centers for planning of students' problems.

\section{Acknowledgment}

The authors profusely thank the personals of counselling services of Ahvaz Jundishapur University for their invaluable contribution in the collection of data.

\section{References}

Arco, J.L., Fernandez, F.D., Heilborn, V.A. \& Lopez, S. (2005) Demographic, Academic and Psychological Profile of Students Attending Counseling Services at the University of Granada (Spain), International Journal for the Advancement of Counseling, 27, 1, pp.71-85.

Atik, G. \& Yalcin, I. (2012) Counseling Needs of educational sciences students at the Ankara University, Procedia social and behavioral sciences, 15, pp. 20-26.

Bahari, F. (2001) Student counselling centers: An analysis of the trend, Teb va Tazkieh, 10, 5, pp. 52-59.

Benton, S.A., Robertson, J.M., Tseng, W.C., Newton, F.B. \& Benton, S.L. (2003) Changes in Counseling Center Client Problems across 13 
Years, Professional Psychology: Research and Practice, 34, 1, pp. 66-72.

Ceyhan, E. \& Eyhan, A. (2011) Loneliness and Depression Levels of Students Usıng a University Counseling Center, Education and Science, 36, 160, pp. 81-92.

Connell, J., Barkham, M. \& Mellor-Clark, J. (2007) CORE-OM mental health norms of students attending university counselling services benchmarked against an age-matched primary care sample, British Journal of Guidance \& Counseling, 35, pp. 41-57.

Cooke, R., Bewick, B. M., Barkham, M., Bradley, M. \& Audin, K. (2006) Measuring, monitoring, and managing the psychological well-being of first year university students, British Journal of Guidance \& Counseling, 34, 4, pp. 505-517.

Daroonparvar, D. (2005) The study of the students' problems of Islamic Azad University, Firoozkuh Branch, and their effect on educational improvement, Quarterly scienctific Journal of Management, 2, 4, pp. 58-64.

Dogan, T., Sari, T., Kazak, M., Saya, P. \& Altintas, T. (2007) The investigation of Baskent University students' problems areas according to class level and gender, Modern Education Journal, 32 , pp. 30-36.

Dogan, T. (2012) A long-term study of the counselling needs of Turkish University students, Journal of Counselling \& Development, 90, pp.91-96.

Fazeli, E. (2004) The Effect of Counseling on University Students, Academic Achievement, Quarterly journal of Research and Planning in Higher Education, 10, 1, pp.61-90.

Ferdowsi, T. (2003) Psychological disorders and problems of students visiting Tehran state universities' consulting centers, Journal of Humanities, 7, pp. 69-95.

Flisher, A.J., De Beer, J.P. \& Bokhorst, F. (2002) Characteristics of students receiving counselling services at the University of Cape Town, South Africa, British Journal of Guidance and Counseling, 30, 3, pp. 299-310.

Giovazolias, T., Leontopoulou, S. \& Triliva, S. (2010) Assessment of Greek University Students' Counseling Needs and Attitudes: An Exploratory Study, International Journal for the Advancement Counseling, 32, pp.101-116.

Guneri, O.Y., Aydın, G. \& Skovholt, T. (2003) Counseling Needs of Students and Evaluation of Counseling Services at a Large Urban University in Turkey, International Journal for the Advancement of Counselling, 25, 1, pp. 5363.
Lucas, M.S. \& Berkel, L.A. (2005) Counseling Needs of students who seek help at a university counseling centers: a closer look at center and multicultural issues, Journal of College student Development, 46, 3, Online, Available at: www.findarticles.com

Mahajan, A.S. (2010) Stress in Medical Education: a global issue or Much Ado about Nothing specific? South East Asian Journal of Medical Education, 4, 2, pp. 78-81.

McCormick, R.M. \& Paterson, D.W. (1996) Student counseling in Canadian Universities, International Journal for the Advancement of Counseling, 18, pp. 235-243.

Naze, M., Khaksari, M., Khaleghi, E. \& Sayadi, A. (2001) A survey on identitying the problems of students at Rafsanjan University of Medical Sciences and their attitude toward the role of counselor in solving their problems, Teb va Tazkieh, 10, 5, pp. 10-15.

Paykari, N., Ramazani, T.F., MalekAfzali, H. \& Jalalinia, S. (2007) The study on key stakeholders' opinion among student counseling centers promotion, Journal of medical council of Islamic Republic of Iran, 25, 4, pp. 431-440.

Quintrell, N. \& Robertson, M. F. (1996) Student counselling in Australian universities: Forty years of development, International Journal for the Advancement of Counseling, 18, pp. 203221.

Raunic, A. \& Xenos, S. (2008) University Counselling Service Utilisation by Local and International Students and User Characteristics: A Review, International Journal of Advance Counselling, 30, pp. 262-267.

Reem, R.A., Eva, M.Z., Elaine, S.Z.F., Gan, N. X. \& Jennie, T.G.L. (2009) A report on stress among first year students in an Indian medical school, South East Asian Journal of Medical Education, 3, 2, pp. 78-81.

Sam, S., Seyfi, S., Ehsani, M. \& Pourghasem, M. (2012) Academic counselors' attitude toward university counseling and counselors duties; Babol dental school, Iranian Quarterly of Education Strategies, 5, 2, pp. 83-88.

Sepahvandi, M.A. (2000) A study on emotional, familial, behavioural and personality characteristics of University student clients visiting the Lorestan University counselling center, Journal of Education and Psychology, 3, $1 \& 2$, pp. 141-150.

Shakurnia, A., Asadollahi, P., Elhampour, H. \& Khodadadi, A. (2011) Present and Desired Status of Student Counseling in Opinions of AJUMS, JSMJ, 10, 5, pp. 469-470. 